\title{
O gênero Bulbophyllum Thouars (Orchidaceae) na Chapada Diamantina, Bahia, Brasil
}

\author{
PATRICIA L. RIBEIRO ${ }^{1,2}$, EDUARDO L. BORBA ${ }^{1}$ e ANTONIO L.V. TOSCANO-DE-BRITO ${ }^{1}$
}

(recebido: 25 de maio de 2004; aceito: 17 de março de 2005)

\begin{abstract}
The genus Bulbophyllum Thouars (Orchidaceae) in the Chapada Diamantina, Bahia, Brazil). The Chapada Diamantina is located in the northern region of the Espinhaço Range, and its main vegetation type is the "campo rupestre", but other vegetational types also occur such as gallery forests, cerrado and caatinga, and the whole region presents high endemism. Bulbophyllum Thouars is the largest genus of Orchidaceae, with nearly 1.200 species. Fifty-eight Bulbophyllum species are recognized from Brazil, and only five of them were until recently reported for the Bahia state. In this study we present a survey of the Bulbophyllum species occurring in the Chapada Diamantina, based on herbarium and field collections. We found 12 Bulbophyllum species and one natural hybrid in the Chapada Diamantina, eight of which are new occurrences for the state. Bulbophyllum epiphytum Barb. Rodr., B. laciniatum (Barb. Rodr.) Cogn., and B. napellii Lindl. are epiphytic; B. involutum Borba, Semir \& F. Barros, B. mentosum Barb. Rodr., B. roraimense Rolfe, B. weddellii (Lindl.) Rchb. f., and B. xcipoense Borba \& Semir occur exclusively as rupicolous; and B. chloropterum Rchb. f., B. cribbianum Toscano, B. ipanemense Hoehne, B. manarae Foldats and B. plumosum (Barb. Rodr.) Cogn. present facultative habit. Bulbophyllum ipanemense is the most abundant species of the genus in the Chapada Diamantina, and the populations of this species in Bahia present several morphological differences in relation to the populations of Southeastern region. B. manarae and B. roraimense, formerly considered as endemic to Venezuela, are mentioned for the first time to Brazil, strengthening the hypothesis of a close relationship between the flora of that country and the Chapada Diamantina.
\end{abstract}

Key words - Bulbophyllum, campo rupestre, Chapada Diamantina, Orchidaceae, taxonomy

RESUMO - (O gênero Bulbophyllum Thouars (Orchidaceae) na Chapada Diamantina, Bahia, Brasil). A Chapada Diamantina localiza-se na porção norte da Cadeia do Espinhaço, tendo como vegetação típica os campos rupestres, mas ocorrendo também em matas de galeria, cerrado e caatinga, possuindo elevado grau de endemismo. O gênero Bulbophyllum Thouars é um dos maiores da família Orchidaceae com aproximadamente 1.200 espécies. No Brasil são reconhecidas cerca de 58 espécies, mas apenas cinco têm sido documentadas para o Estado da Bahia. Neste trabalho foi realizado o levantamento das espécies de Bulbophyllum da Chapada Diamantina, através de coletas e coleções de herbário. Foram encontradas 12 espécies e um híbrido natural na Chapada Diamantina, sendo oito citações novas para o estado. Bulbophyllum epiphytum Barb. Rodr., B. laciniatum (Barb. Rodr.) Cogn. e B. napellii Lindl. possuem hábito epifítico; B. involutum Borba, Semir \& F. Barros, B. mentosum Barb. Rodr., B. roraimense Rolfe, $B$. weddellii (Lindl.) Rchb. f. e $B . \times$ cipoense Borba \& Semir ocorrem exclusivamente como rupícolas; já B. chloropterum Rchb. f., B. cribbianum Toscano, B. ipanemense Hoehne, B. manarae Foldats e B. plumosum (Barb. Rodr.) Cogn. possuem hábito facultativo. Bulbophyllum ipanemense é a espécie mais abundante na Chapada Diamantina, e as populações da Bahia apresentam uma ampla variação morfológica em relação às populações da região Sudeste. Bulbophyllum manarae e $B$. roraimense consideradas endêmicas da Venezuela, são citadas pela primeira vez para o Brasil, fortalecendo a hipótese de uma estreita relação entre as formações deste país e da Chapada Diamantina.

Palavras-chave - Bulbophyllum, campo rupestre, Chapada Diamantina, Orchidaceae, taxonomia

\section{Introdução}

O complexo montanhoso da Chapada Diamantina corresponde à porção norte da Cadeia do Espinhaço no Estado da Bahia, possuindo extensão aproximada de

1. Universidade Estadual de Feira de Santana, Departamento de Ciências Biológicas, Laboratório de Taxonomia Vegetal, Rodovia BR 116, km 3, Campus Universitário, 44031-460 Feira de Santana, BA, Brasil.

2. Autor para correspondência: patyluzribeiro@yahoo.com.br
$330 \mathrm{~km}$ na direção norte-sul. A Chapada Diamantina apresenta uma diversidade de climas e topografia que proporciona elevada variedade de padrões fitofisionômicos. O tipo vegetacional predominante é o campo rupestre, geralmente acima de $900 \mathrm{~m}$ de altitude, embora ocorram também campos cerrados ("gerais"), cerrados de altitude e diferentes tipos de florestas como as pluvio-nebulares, ciliares e as de grotão. As formações florestais da Chapada Diamantina são altamente influenciadas pela umidade atmosférica e, segundo Harley (1995), podem ser ricas em epífitas, incluindo bromélias, orquídeas, antúrios, peperômias, 
pteridófitas e briófitas. A caatinga também ocorre na Chapada Diamantina, principalmente na vertente leste (Grillo 2000), em áreas de menor altitude. Os campos rupestres não contêm uma vegetação homogênea e sim um mosaico de comunidades relacionadas (Harley 1995). São características de campos rupestres, vegetação subarbustiva e herbácea em solo arenoso pedregoso e arbustiva e herbácea em ilhas de afloramentos rochosos de quartzito, arenito ou canga (Giulietti \& Pirani 1988, Borba \& Semir 1998b, Borba et al. 2001b).

A família Orchidaceae é bem representada nos tipos vegetacionais da Chapada Diamantina, principalmente nas matas e nos campos rupestres, sendo uma das principais famílias em número de espécies, inferior apenas a Poaceae e Asteraceae (Conceição \& Giulietti 2002), o que mostra a grande importância de um estudo mais profundo dos gêneros ali ocorrentes. Segundo Harley (1995), os gêneros de orquídeas mais comuns nos campos rupestres são Bulbophyllum, Cyrtopodium, Epidendrum, Laelia (Sophronitis, sensu van den Berg \& Chase 2000), Oncidium, Pleurothallis (Acianthera, sensu Pridgeon \& Chase 2001), Specklinia e Zygopetalum.

O gênero Bulbophyllum Thouars é um dos mais representativos em número de espécies, com aproximadamente 1.200 espécies. Possui distribuição pantropical, com grande parte de seus representantes distribuídos principalmente na Ásia e Oceania, com um número inferior de espécies na África e nas Américas (Dressler 1981, 1993, Vermeulen 1991). Para o Brasil, Pabst \& Dungs $(1975,1977)$ listaram 54 espécies, distribuídas principalmente entre os Estados do Rio de Janeiro, São Paulo e Minas Gerais, não sendo mencionada nenhuma espécie para a Bahia. Este número foi acrescido para cerca de 60 espécies por algumas publicações posteriores (e.g., Borba et al. 1998, Toscano-de-Brito 2000). Toscano-de-Brito (1995) listou as primeiras três espécies para o Estado da Bahia, encontradas em campos rupestres do Pico das Almas, Chapada Diamantina: B. cribbianum Toscano, B. weddellii (Lindl.) Rchb.f. e B. ipanemense Hoehne, sendo posteriormente acrescentadas $B$. involutum Borba, Semir \& F.Barros (Borba et al. 1998) e B. kautskyi Toscano (Toscano-de-Brito 2000), esta última para a Mata Atlântica, além do híbrido natural B. $\times$ cipoense Borba \& Semir (Azevedo 2004).

As espécies de Bulbophyllum no Brasil ocorrem tipicamente com hábito epífita em matas, ou rupícola em afloramentos rochosos de campos rupestres. Muitas espécies que ocorrem em campos rupestres, especialmente as rupícolas, encontram-se distribuídas em populações disjuntas, devido à descontinuidade das cadeias montanhosas e destes afloramentos rochosos (Borba et al. 2001a). Alguns autores relacionam essa característica com o elevado grau de endemismo observado nessa formação (Joly 1970, Giulietti \& Pirani 1988, Harley 1988). A falta de uma revisão taxonômica recente, aliada à escassez de coletas, tem acarretado uma baixa amostragem da variação intraespecífica, gerando dificuldades na interpretação de várias espécies brasileiras e conseqüentemente a determinações errôneas de espécimes de herbário (Borba et al. 1998). Este problema é particularmente expressivo em alguns grupos de espécies brasileiras do gênero, nos quais elas se apresentam vegetativamente uniformes e a separação é apenas possível por características florais de difícil reconhecimento em material de herbário, apesar de diagnose relativamente fácil de algumas delas a partir de material vivo (Borba et al. 1998). Para tanto, é necessária a realização de estudos taxonômicos acurados, sem desprezar a utilização de abordagens biossistemáticas na solução de problemas taxonômicos (Borba \& Semir 1998a, b, Borba et al. 1998, 2002, Silva et al. 1999).

O presente trabalho objetivou a realização de um levantamento das espécies de Bulbophyllum da Chapada Diamantina, sendo fornecidas descrições, ilustrações, chave de identificação e mapa de distribuição das espécies.

\section{Material e métodos}

Foram realizadas coletas na Chapada Diamantina, sendo amostrados principalmente os Municípios de Morro do Chapéu, Lençóis, Mucugê, Rio de Contas e Palmeiras. Os espécimes em floração receberam o tratamento convencional de herborização segundo Mori et al. (1985) e foram incorporados ao acervo do Herbário da Universidade Estadual de Feira de Santana (HUEFS). Todas as espécies coletadas estão sendo cultivadas na casa de vegetação da UEFS para estudos futuros de biossistemática, genética e biologia reprodutiva. Foram examinados materiais do gênero Bulbophyllum presentes nas coleções dos herbários HUEFS, ALCB, HRB, SP, UEC, CEPEC e BHCB (siglas segundo Holmgreen et al. 1990). Foram confeccionadas descrições, ilustrações, chave de identificação e mapas de distribuição das espécies de Bulbophyllum encontradas na Chapada Diamantina.

\section{Resultados e Discussão}

Foram encontrados 13 táxons do gênero Bulbophyllum na Chapada Diamantina, sendo 12 
espécies e um híbrido natural (figura 1). Destes, oito táxons não haviam sido citados para a Bahia, entre eles um híbrido natural e duas espécies ainda não citadas para o Brasil, aumentando a lista do estado para 14 táxons. De aproximadamente 60 espécies citadas para o Brasil, a Chapada Diamantina apresenta cerca de $21 \%$ delas. A Chapada Diamantina apresenta 10 táxons (77\%) comuns a Minas Gerais, o estado com maior número de espécies (ca. 33), apesar da barreira de migração entre as massas montanhosas da Bahia e de Minas Gerais (Harley 1988).

A Chapada Diamantina se apresenta em formato de Y, no sentido norte-sul, e todos os espécimes encontrados estão localizadas na vertente leste (figura 1). Rio de Contas é o município onde se concentra o maior número de táxons (sete), seguido por Mucugê (quatro), Morro do Chapéu (três), Abaíra (três), Palmeiras (três), Piatã (dois), Lençóis (um), Seabra (um), Jacobina (um) e Umburanas (um). Algumas localidades da Chapada Diamantina tiveram uma maior quantidade de coletas, favorecidas por projetos específicos, como é o caso de Rio de Contas e Mucugê. Dessa forma, a baixa frequiência ou a inexistência de espécies em outras localidades da Chapada Diamantina pode estar relacionada à escassez de coletas. A baixa freqüência de espécies em certas regiões da Chapada Diamantina pode ser explicada pelas variações de umidade nas vertentes leste e oeste. De acordo com Harley (1995) e Grillo (2000), as regiões a leste da Chapada Diamantina estão sujeitas a maior umidade do que aquelas a oeste, devido à passagem de umidade vinda do oceano. Segundo Pabst \& Dungs (1975), a umidade é o fator mais evidente que pode interferir na diversidade de orquídeas de uma região.

Cinco táxons, B. involutum Borba, Semir \& F.Barros, B. mentosum Barb. Rodr., B. roraimense Rolfe, B. weddellii (Lindl.) Rchb. f. e B. xcipoense Borba \& Semir, ocorrem exclusivamente como rupícolas em rochas nuas ou associadas à pouca quantidade de solo predominantemente orgânico fibroso (Conceição \& Giulietti 2002) e arenoso sobre os afloramentos rochosos. As espécies exclusivamente epífitas, B. epiphytum Barb. Rodr., B. laciniatum (Barb. Rodr.) Cogn. e B. napellii Lindl. ocorrem em matas mais úmidas como matas de galeria e matas de grotão. As demais espécies têm hábito facultativo epífita e rupícola, como B. chloropterum (Barb. Rodr.) Cogn., B. cribbianum Toscano, B. ipanemense Hoehne, B. manarae Foldats e B. plumosum (Barb. Rodr.) Cogn.

Bulbophyllum manarae e B. roraimense, até o presente, eram consideradas espécies exclusivas da Venezuela (Dunsterville \& Garay 1979), ainda não citadas para o Brasil, apesar da última poder ocorrer também na Amazônia brasileira. Embora sejam áreas

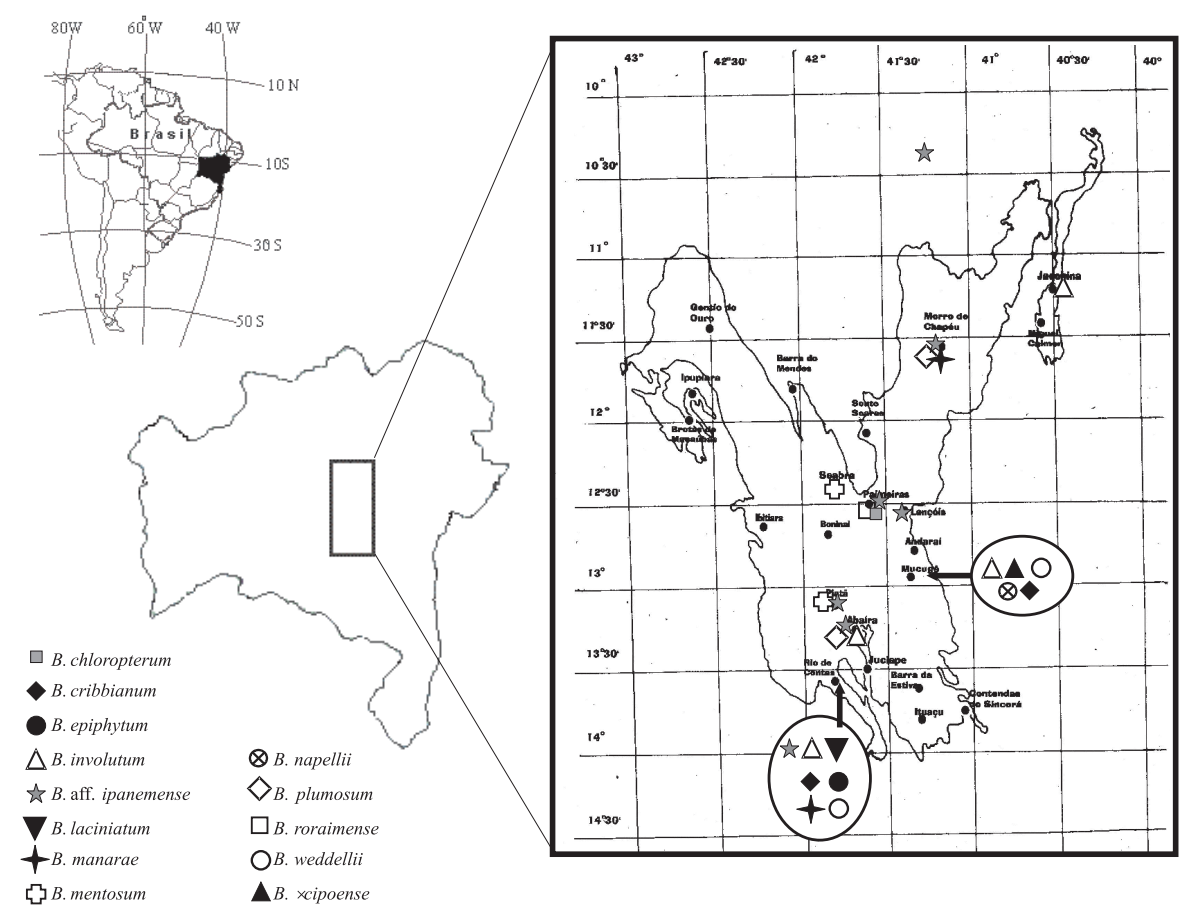

Figura 1. Mapa de distribuição das espécies de Bulbophyllum (Orchidaceae) da Chapada Diamantina, Bahia.

Figure 1. Map of distribution of the Bulbophyllum (Orchidaceae) species from the Chapada Diamantina, Bahia. 
bastante disjuntas, existem algumas espécies que apresentam este tipo de distribuição, por exemplo, Eriope crassipes Benth. e Hyptis salzmannii Benth. Labiatae (Harley 1988). Essa disjunção de espécies entre a Serra do Espinhaço, norte da América do Sul, Guianas e Venezuela também tem sido mencionada para outras famílias, como Fabaceae (Chamaecrista), Xyridaceae (Xyris) e Eriocaulaceae (Leiothrix), e foi considerada por Giulietti \& Pirani (1988) como um padrão de distribuição característico na flora dos campos rupestres. De acordo com Harley (1988), flutuações climáticas no Pleistoceno seriam responsáveis por este padrão de distribuição atual destas espécies.

Bulbophyllum Thouars, Orch. Iles Afr. Tab. Esp. 3 et Ic. t. 93-97. 1822.

Ervas. Raízes fasciculadas. Rizoma horizontal. Pseudobulbos eretos, carnosos, piriformes, tetrágonos, monófilos. Folha apical, séssil, conduplicada, base atenuada e canaliculada. Inflorescência basal. Flores com sépalas côncavas; pétalas membranáceas; labelo móvel, articulado com o pé da coluna, carnoso, usualmente trilobado. Coluna ereta; antera terminal, versátil, dois pares de polínias desiguais, nuas.

Chave para os táxons de Bulbophyllum da Chapada Diamantina

1. Rizoma curto, até $0,7 \mathrm{~cm}$ compr. entre pseudobulbos, pseudobulbos agregados

2. Sépalas e labelo acima de $1,3 \mathrm{~cm}$ compr.

3. Labelo inteiramente carnoso; pétala panduriforme

6. B. laciniatum

3. Lobo mediano do labelo membranáceo; pétala oval-lanceolada a lanceolada

4. Ápice do lobo mediano do labelo agudo, calo extendendo-se até a metade do labelo; pétalas curto-ciliadas (figura 2B)

1. B. chloropterum

4. Ápice do lobo mediano do labelo arredondado, calo extendendo-se até 1/4 do labelo; lobos laterais do labelo e pétalas densamente longo-ciliadas (figura 2I) 10. B. plumosum

2. Sépalas e labelo até $0,7 \mathrm{~cm}$ compr.

5. Folhas cartáceas, planas; presença de dois dentes na margem da face ventral da coluna; sépalas laterais unidas em toda extensão; flores púrpura

7. B. manarae

5. Folhas carnosas, cilíndricas; coluna sem dentes na margem da face ventral; sépalas laterais unidas apenas na base; flores brancas

3. B. epiphytum

1. Rizoma longo, acima de $1 \mathrm{~cm}$ compr. entre pseudobulbos, pseudobulbos não agregados

6. Pseudobulbos com até $1,5 \mathrm{~cm}$ altura; inflorescência com uma ou duas flores

7. Pseudobulbos muito mais longos do que largos (figura 5I); folhas oblongas; pétalas ca. $3 \mathrm{~mm}$ compr.; ápice do labelo retuso 9. B. napellii

7. Pseudobulbos com largura similar à altura (figura 3A); folhas ovado-elípticas; pétalas com até $0,5 \mathrm{~mm}$ compr.; ápice do labelo arredondado 2. B. cribbianum

6. Pseudobulbos com mais de $2 \mathrm{~cm}$ altura; inflorescência com mais de oito flores

8. Inflorescência genuflexa com raque pendente

9. Pétalas e sépalas eretas, carnosas; flor ligeiramente tubular; 1 a 2 flores em antese concomitantemente; pétalas acima de $5 \mathrm{~mm}$ compr., oblongo-ovada, margem ciliada; labelo até $3 \mathrm{~mm}$ compr., carnoso, lobo mediano revoluto com margem emarginada, obcordada 8. B. mentosum

9. Pétalas e sépalas laterais patentes e dorsal ereta, não carnosas; flor não tubular; acima de 4 flores em antese concomitantemente; pétalas até $3 \mathrm{~mm}$ compr., triangulares, falcadas, margem inteira; labelo acima de $10 \mathrm{~mm}$ compr., lobo mediano plano e membranáceo, ápice subagudo 12. B. weddellii

8. Inflorescência ereta a curvada

10. Flores predominantemente púrpura com manchas amarelas

11. Pétalas ovadas, ápice obtuso a subagudo; base do lobo mediano do labelo truncada, margem inteira 4. B. involutum

11. Pétalas lanceolado-triangulares, ápice agudo; base do lobo mediano do labelo atenuada, margem ciliada 13. B. $\times$ cipoense

10. Flores predominantemente amarelas com manchas púrpura 
12. Inflorescência ereto-patente; pétala lanceolado-triangular; lobo mediano do labelo com margem ondulada e levemente involuta, ápice arredondado 5. B. ipanemense

12. Inflorescência ereta; pétala oblongo-ovada; lobo mediano do labelo revoluto, ápice agudo 11. B. roraimense

1. Bulbophyllum chloropterum Rchb. f., Linnaea 22:835. 1849.

Figura 2A-C.

Epífita. Rizoma 0,4-0,5 cm compr. entre os pseudobulbos, 0,15-0,2 cm diâm. Pseudobulbos 1,0-1,5 cm alt., levemente rugosos, agregados, verdes. Folha 5-6 $\times$ 0,7 cm, ereto-patente, cartácea, oblonga, ápice acuminado. Inflorescência: escapo 7,5-9 cm compr., ereto; raque 3-5 cm compr., ligeiramente arqueado, 4-7 flores, antese simultânea. Flores pendentes; ovário (hipanto) mais pedicelo 2-3 mm compr., obcônico, curvado e sulcado longitudinalmente, verde; sépalas ereto-patentes, cartáceas, espessas, lineares, ápice agudo, verdes; sépala dorsal $17 \times 2 \mathrm{~mm}$; sépalas laterais $17 \times 3-3,5 \mathrm{~mm}$, fundidas lateralmente; pétalas 4-5 × $2 \mathrm{~mm}$, eretas, oval-lanceoladas, assimétricas, verdes, ápice agudo, base arredondada, margem curto-ciliada; labelo 13-16 × 1-2 mm, linear; lobos laterais eretos; metade proximal calosa, carnosa, calo ca. $1 \mathrm{~mm}$ alt., verde com manchas púrpura; lobo mediano membranáceo, linear, branco e maculado de púrpura, ápice agudo, base atenuada e ondulada; coluna 3-4 × 1-2 mm, dois braços eretos no ápice e dois dentes eretos na face ventral, esverdeada, branca na base e face dorsal púrpura.

Material examinado: BRASIL. BAHIA: Palmeiras, Rio Santo Antônio, Poço Mãe d'Água, 22-XII-1996, A.L.V. Toscano-de-Brito 1051 (HUEFS); 1997, A.L.V. Toscano-de-Brito 1792 (HUEFS).

Bulbophyllum chloropterum ocorre como epífita em matas de galeria de Minas Gerais (Pabst \& Dungs 1975) e Bahia, onde é citado pela primeira vez. Espécie incluída na sect. Xiphizusa (Pabst \& Dungs 1975) e pertencente a um complexo de taxonomia controversa, sendo semelhante a B. laciniatum e B. plumosum, diferenciando-se destas principalmente pelo labelo com região calosa estendendo-se até a metade deste e por possuir tricomas curtos nas pétalas e labelo glabro. Floresce em dezembro.

2. Bulbophyllum cribbianum Toscano, Kew Bull. 47(4):774. 1992.

Figura 3A-D.

Epífita, raramente rupícola. Rizoma 1,5-2,5 cm compr. entre pseudobulbos, 0,1-0,2 cm diâm.
Pseudobulbos 0,6-1,5 cm, rugosos, castanhoesverdeados. Folha 1,5-2,5 $\times 0,7-1,5 \mathrm{~cm}$, ereto-patente, cartácea, ovado-elíptica, ápice acuminado. Inflorescência: escapo 3-7 cm compr., ereto na base e curvado no ápice; raque 1,5-2,5 cm compr., 1-2 flores. Flores ressupinadas por curvamento da raque; ovário (hipanto) mais pedicelo 1-2 mm compr., obcônico, verde; sépalas ereto-patentes, levemente espessas, deltóides, apiculadas, rosa ou amareladas com veios púrpura; sépala dorsal 5-6 × 5,5-6 mm, livre; sépalas laterais 7-7,5 × 5-6 mm, ligeiramente falcadas; pétalas $0,3 \times$ $1 \mathrm{~mm}$, eretas, deltóides, ápice subagudo, base assimétrica, margem inteira; labelo 5-6×3-4 mm, inteiro, falcado, carnoso a levemente cartáceo, sulcado longitudinalmente até $2 / 3$ de sua extensão, margem do terço proximal ereta, porção distal convexa, paralelo à coluna, ápice arredondado, margem inteira; coluna 2-3 $\times$ 1-1,5 mm, sem braços nem dentes, levemente alada, côncava.

Material examinado: BRASIL. BAHIA: Mucugê, Guiné, 10-XI-2001, E.L. Borba et al. 2127 (HUEFS); Parque Municipal de Mucugê, mata de grotões, 26-XI-2002, C. Azevedo 167 (HUEFS); Rio de Contas, base do Pico das Almas, caminho para o Queiroz, 8-VIII-1998, A.L.V. Toscano-de-Brito 1806 (HUEFS).

Bulbophyllum cribbianum é encontrado epífita em matas de galeria e Mata Atlântica dos estados da Bahia, Rio de Janeiro, Minas Gerais, São Paulo e Espírito Santo (Pabst \& Dungs 1975, Toscano-de-Brito 1995). É caracterizada pelas pétalas de tamanho extremamente reduzido e pelo longo pé da coluna. Espécie incluída na sect. Bulbophyllaria (Pabst \& Dungs 1975). B. cribbianum é um nome novo para $B$. micropetalum Barb. Rodr., nome pré-ocupado por uma espécie asiática. É muito semelhante a B. micropetaliforme J.E. Leite, diferenciando-se basicamente pelos pseudobulbos agregados, distanciados em apenas $0,3 \mathrm{~cm}$ em B. micropetaliforme (Cogniaux 1898-1902). Floresce de agosto a novembro.

3. Bulbophyllum epiphytum Barb. Rodr., Gen. Sp. Orchid. 1:40. 1877.

Figura 3E-H.

Epífita. Rizoma 0,3-0,5 cm compr. entre os pseudobulbos, $0,2 \mathrm{~cm}$ diâm. Pseudobulbos ca. 1,5 cm 

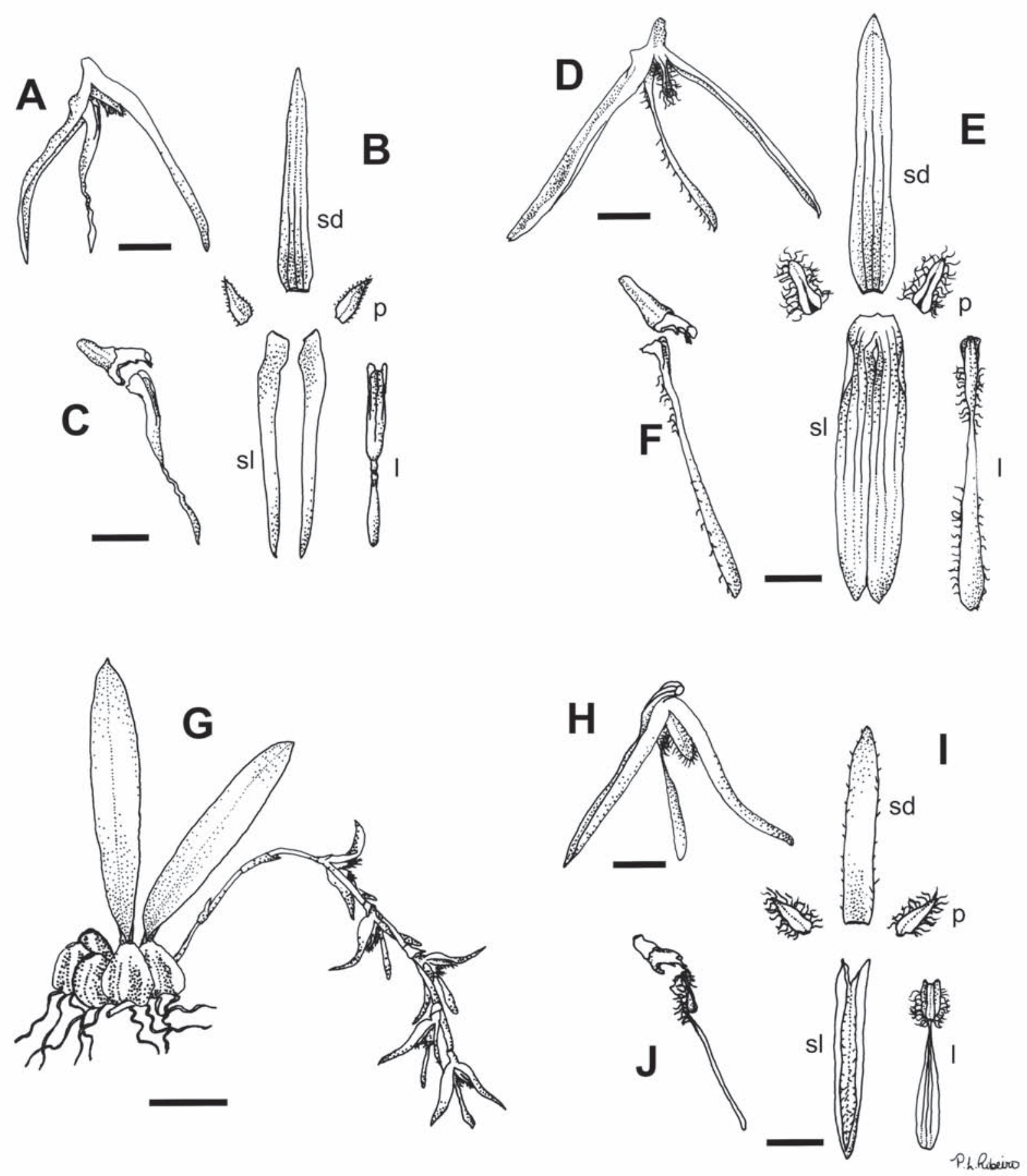

Figura 2. A-C. Bulbophyllum chloropterum. A. Flor, em posição natural. B. Peças do perianto. C. Coluna e labelo, vista lateral. D-F. B. laciniatum. D. Flor, em posição natural. E. Peças do perianto. F. Coluna e labelo, vista lateral. G-J. B. plumosum. G. Hábito. H. Flor, em posição natural. I. Peças do perianto. J. Coluna e labelo, vista lateral. 1 = labelo, $p=$ pétala, sd = sépala dorsal, sl = sépala lateral. O labelo é apresentado em ângulo com a coluna de acordo com sua posição original, tendo sido destacado para facilitar a visualização de detalhes. Barras = $5 \mathrm{~mm}$ (A-F, H-J), $20 \mathrm{~mm}$ (G). (A-C: Toscano-de-Brito 1051; D-F: Toscano-de-Brito 1907; G-J: Ganev 3003).

Figure 2. A-C. Bulbophyllum chloropterum. A. Flower, natural position. B. Perianth parts. C. Column and lip, side view. D-F. B. laciniatum. D. Flower, natural position. E. Perianth parts. F. Column and lip, side view. G-J. B. plumosum. G. Habit. H. Flower, natural position. I. Perianth parts. J. Column and lip, side view. $1=\mathrm{lip}, \mathrm{p}=$ petal, $\mathrm{sd}=\mathrm{dorsal}$ sepal, $\mathrm{sl}=$ lateral sepal. The lip is presented in angle with the column in accordance to its original position, and it was detached to show morphological details. Bars = 5 mm (A-F, H-J), 20 mm (G). (A-C: Toscano-de-Brito 1051; D-F: Toscano-de-Brito 1907; G-J: Ganev 3003). 


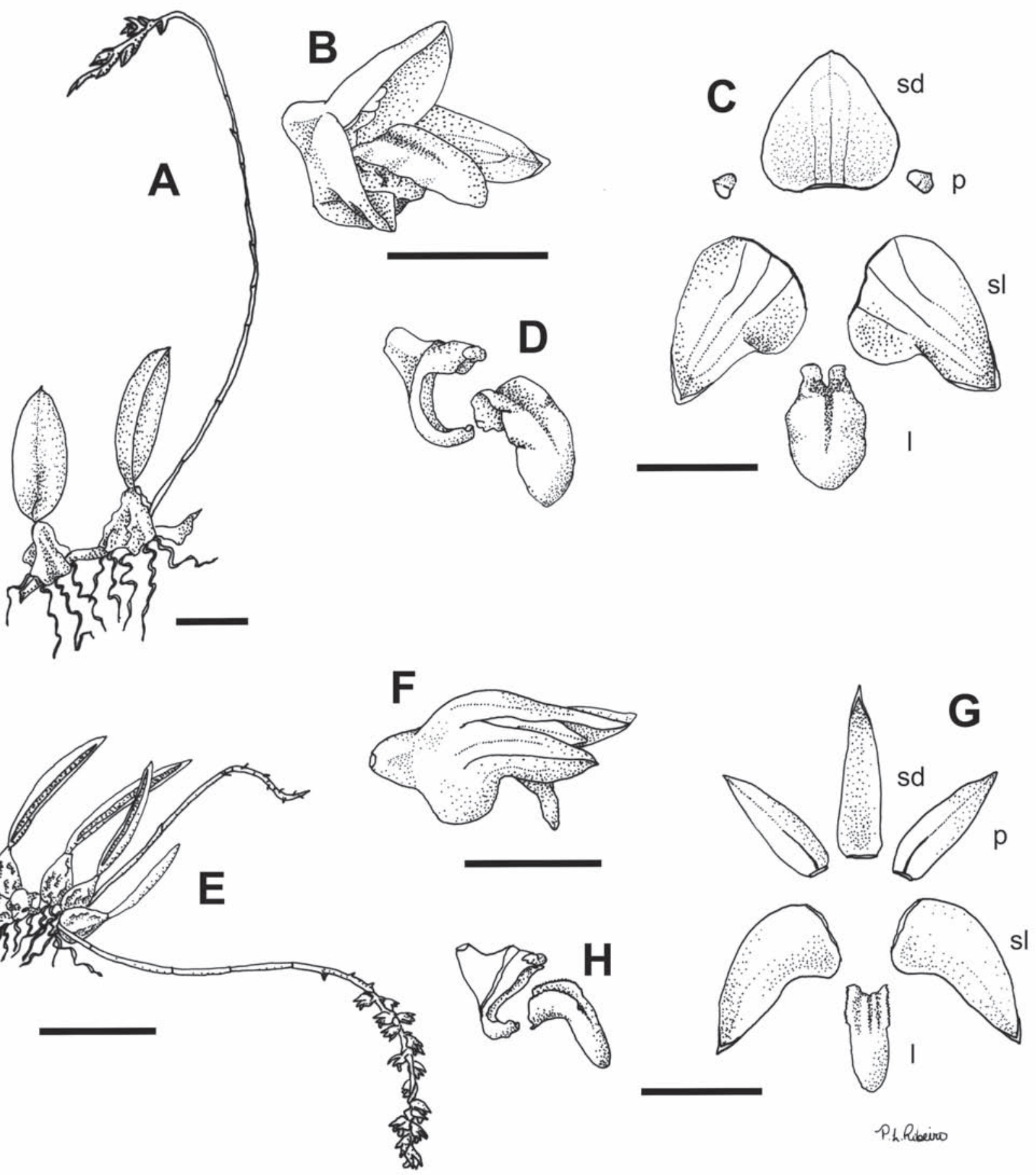

Figura 3. A-D. Bulbophyllum cribbianum. A. Hábito. B. Flor. C. Peças do perianto. D. Coluna e labelo, vista lateral. E-H. B. epiphytum. E. Hábito. F. Flor. G. Peças do perianto. H. Coluna e labelo, vista lateral. $1=$ labelo, p = pétala, sd = sépala dorsal, sl = sépala lateral. O labelo é apresentado em ângulo com a coluna de acordo com sua posição original, tendo sido destacado para facilitar a visualização de detalhes. Barras $=5 \mathrm{~mm}$ (B-D, F-H), $20 \mathrm{~mm}$ (A, E). (A-D: Borba et al. 2127; E-H: Toscanode-Brito 1851).

Figure 3. A-D. Bulbophyllum cribbianum. A. Habit. B. Flower. C. Perianth parts. D. Column and lip, side view. E-H. B. epiphytum. E. Habit. F. Flower. G. Perianth parts. H. Column and lip, side view. $1=$ lip, $\mathrm{p}=$ petal, $\mathrm{sd}=$ dorsal sepal, $\mathrm{sl}=$ lateral sepal. The lip is presented in angle with the column in accordance to its original position, and it was detached to show morphological details. 4Bars = 5 mm (B-D, F-H), 20 mm (A, E). (A-D: Borba et al. 2127; E-H: Toscano-de-Brito 1851). 
alt., ovado-globosos, agregados. Folha ca. 4,3 $\times 0,4 \mathrm{~cm}$, ereta, rígida, carnosa, cilíndrica, ápice agudo. Inflorescência: escapo 10-13 cm compr., curvado, rígido; raque 7-9 cm compr., curvada, 25-33 flores com antese simultânea. Flores tubulares, ressupinadas por curvatura da inflorescência; ovário (hipanto) mais pedicelo $1 \mathrm{~mm}$ compr., obcônico; sépalas eretas, membranáceas, brancas, ápice acuminado; sépala dorsal ca. $5 \times 1 \mathrm{~mm}$, lanceolada; sépalas laterais ca. 4,5 × $2 \mathrm{~mm}$, ovallanceoladas, falcadas, base assimétrica, unidas na base formando um pequeno mento; pétalas ca. 3,5 ×1 mm, eretas, lanceoladas, ápice agudo, base arredondada, margem inteira; labelo ca. $2,5 \times 1 \mathrm{~mm}$, falcado, sulcado longitudinalmente, indiviso, carnoso, amarelado, metade proximal paralela à coluna com margem ereta $\mathrm{e}$ serrilhada; metade distal patente, ápice obtuso; coluna ca. $0,8 \times 0,1 \mathrm{~mm}$, com dois braços, eretos, sem dentes na face ventral, curtamente alada.

Material examinado: BRASIL. BAHIA: Rio de Contas, Ponte do Coronel, 18-X-1998, A.L.V. Toscanode-Brito 1851 (HUEFS).

Bulbophyllum epiphytum é uma epífita de ocorrência comum em matas de galeria do sul de Minas Gerais, além de São Paulo e Goiás (Pabst \& Dungs 1975). Está inserida na sect. Micrantha (Pabst \& Dungs 1975), em um grupo de espécies afins constituído por B. micrantum Barb. Rodr., B. punctatum Barb. Rodr. e B. rupicolum Barb. Rodr. Esta última é a mais semelhante, diferenciando-se de B. epiphytum principalmente pelo hábito, que caracteriza seus epítetos específicos e pelas folhas pouco mais curtas em B. rupicolum. Floresce em outubro.

4. Bulbophyllum involutum Borba, Semir \& F. Barros, Novon 8(3):225. 1998.

Figura 4A-C.

Rupícola. Rizoma 1,5-3 cm compr. entre pseudobulbos, 0,4-0,5 cm diâm. Pseudobulbos 2,5-5 cm alt., verde-amarelados. Folha 7-10 × 2,5-3,5 cm, ereta, espessa, oblonga, ápice acuminado. Inflorescência: escapo 18-32 cm compr., ereto, rígido, púrpura; raque 30-37 cm compr., 12-15 flores, raque púrpura, ereta. Flores ressupinadas por torção do pedicelo, apenas uma flor em antese (muito raramente duas); ovário (hipanto) mais pedicelo 4-7 mm compr., obcônico, púrpura; sépalas cartáceas, espessas, naviculadas, oval-lanceoladas, púrpura com manchas esverdeadas, ápice acuminado, base arredondada; sépala dorsal 10-13 × 4-5 mm, ereta; sépalas laterais $11-13 \times 4-5 \mathrm{~mm}$, patentes, levemente falcadas, oblíquas; pétalas 4-5×2-3 mm, ereto-patentes, ovadas, brancas com manchas púrpura, ápice obtuso a subagudo, margem curto-ciliada; labelo 6-7 × 3-4 mm, trilobado, carnoso, púrpura com ápice branco; lobos laterais eretos, auriculares, curto-ciliados; lobo mediano carnoso na região calosa, ápice obtuso, base truncada, calo púrpura escuro, ca. $2 \mathrm{~mm}$ alt., margens freqüentemente onduladas, margem lateral involuta; coluna 5-6 × 1-2 mm, dois braços eretos, sinuosos e dois dentes falcados sob os braços na face ventral.

Material examinado: BRASIL. B AHIA: Abaíra, estrada para Catolés-Morro da Boa Vista, 4-IV-1992, W. Ganev 26 (HUEFS); Jambeiro, 31-V-1994, W. Ganev 3002 (HUEFS); Jacobina, estrada para Morro do Chapéu, 7-VI-2001, M.E.R. Junqueira 59 (HUEFS); Mucugê, Parque Municipal de Mucugê, Sandália Bordada, 17-IX-2002, C. Azevedo 149 (HUEFS); Rio de Contas, Ponte do Coronel, margens do Rio Brumadinho, 9-I-2000, A.L.V. Toscano-de-Brito 2143 (HUEFS); A.L.V. Toscano-de-Brito 2296 (HUEFS).

Bulbophyllum involutum pertence a um complexo de taxonomia confusa formado por $B$. ipanemense Hoehne, B. warmingianum Rchb.f., B. longispicatum Cogn. e B. geraense Rchb.f. Foi recentemente descrito com base em estudos de biossistemática, sendo encontrado apenas na Cadeia do Espinhaço, em Minas Gerais e Bahia (Borba et al. 1998). Diferencia-se de B. ipanemense principalmente pelas pétalas ovadas com ápice obtuso e labelo com margem lateral involuta, pela coloração púrpura da raque, brácteas e sépalas, e por possuir apenas uma flor em antese por inflorescência. Eventualmente hibridiza na natureza com $B$. weddellii, dando origem a $B . \times$ cipoense Borba \& Semir (Borba \& Semir 1998a). Em Mucugê, onde também foi detectada hibridação com $B$. weddellii, os híbridos originados retrocruzam com $B$. involutum, causando introgressão de genes de $B$. weddellii nesta espécie, refletida no aumento de sua variabilidade morfológica (Azevedo 2004; C.O.Azevedo, E.L. Borba \& C. van den Berg, submetido).

5. Bulbophyllum ipanemense Hoehne, Arq. Bot. Estado São Paulo, 1(1):20. 1938.

Figura 4D-G.

Rupícola, eventualmente epífita. Rizoma 1,5-2,5 cm compr. entre pseudobulbos, 0,4-0,5 cm diâm. Pseudobulbos 2,5-4,2 cm alt., verde-amarelados. Folha 6-10 × 2,5-3 cm, ereto-patente, espessa, oblonga, ápice agudo-acuminado. Inflorescência: escapo $25-62 \mathrm{~cm}$ compr., ereto-patente, rígido, amarelado; raque 


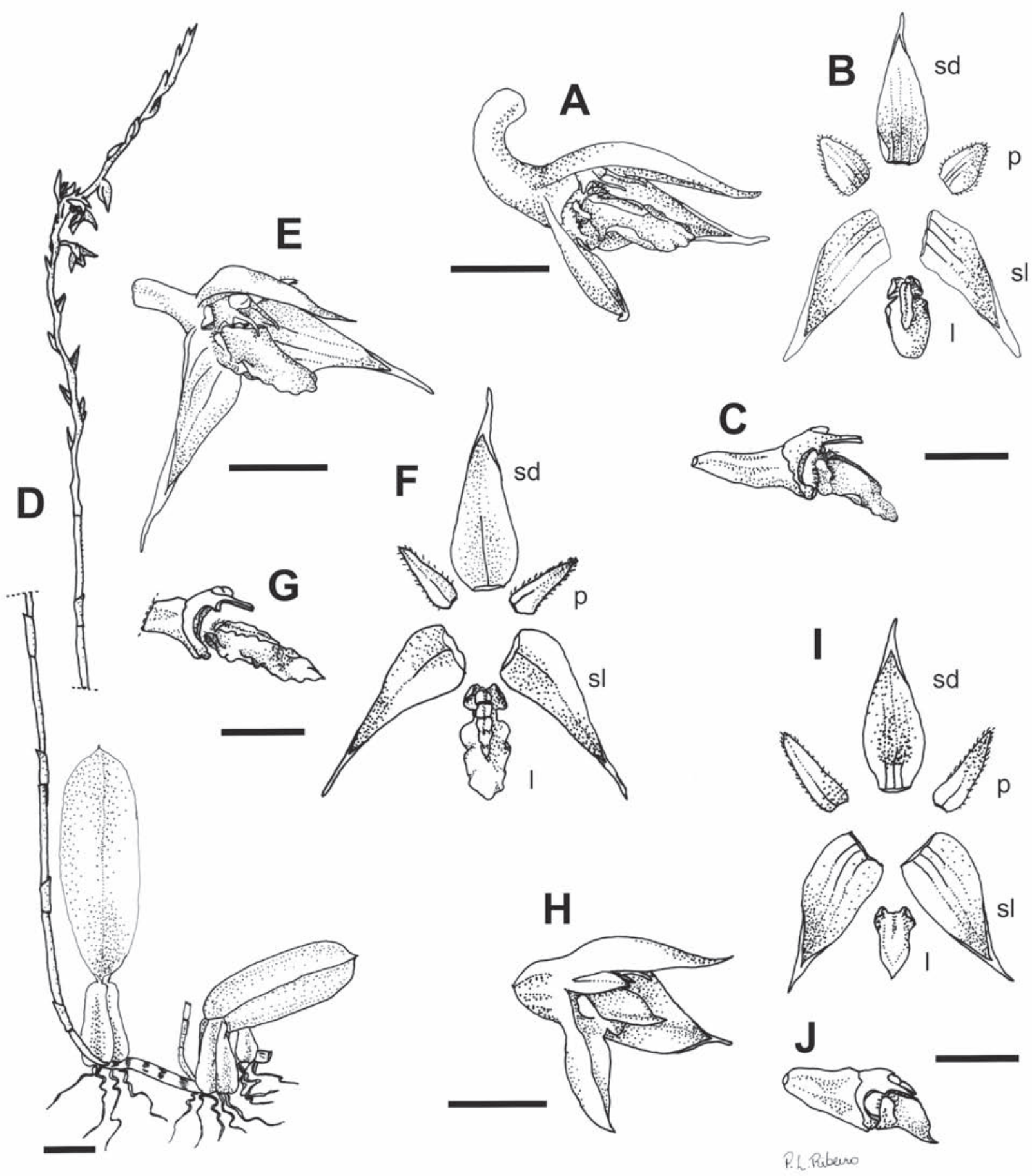

Figura 4. A-C. Bulbophyllum involutum. A. Flor. B. Peças do perianto. C. Coluna e labelo, vista lateral. D-G. B. ipanemense. D. Hábito E. Flor. F. Peças do perianto. G. Coluna e labelo, vista lateral. H-J. B. roraimense. H. Flor. I. Peças do perianto. J. Coluna e labelo, vista lateral. $\mathrm{l}=$ labelo, $\mathrm{p}=$ pétala, $\mathrm{sd}=$ sépala dorsal, $\mathrm{sl}$ = sépala lateral. O labelo é apresentado em ângulo com a coluna de acordo com sua posição original, tendo sido destacado para facilitar a visualização de detalhes. Barras $=5 \mathrm{~mm}$ (A-C, E-J), 20 mm (D). (A-C: Toscano-de-Brito 2143; D-G: Ribeiro 27; H-J: Toscano-de-Brito 1800).

Figure 4. A-C. Bulbophyllum involutum. A. Flower. B. Perianth parts. C. Column and lip, side view. D-G. B. ipanemense. D. Habit. E. Flower. F. Perianth parts. G. Column and lip, side view. H-J. B. roraimense. H. Flower. I. Perianth parts. J. Column and lip, side view. $\mathrm{l}=$ lip, $\mathrm{p}=$ petal, $\mathrm{sd}=$ dorsal sepal, $\mathrm{sl}=$ lateral sepal. The lip is presented in angle with the column in accordance to its original position, and it was detached to show morphological details. Bars $=5 \mathrm{~mm}$ (A-C, E-J), $20 \mathrm{~mm}$ (D). (A-C: Toscanode-Brito 2143; D-G: Ribeiro 27; H-J: Toscano-de-Brito 1800). 
18-25 cm compr., 18-35 flores, raque amarelada, 3-6 flores em antese. Flores ressupinadas por torção do pedicelo e, eventualmente, curvamento da inflorescência; ovário (hipanto) mais pedicelo 4-7 mm compr., obcônico, torcido, amarelado; sépalas cartáceas, espessas, naviculadas, ápice acuminado, base arredondada, face dorsal verde-amarelada, face ventral com manchas púrpura transversais na base e ápice púrpura; sépala dorsal 8-14 × 3-4 mm, ereta, ovallanceolada; sépalas laterais 8-10 × 3-5 mm, patentereflexas, lanceolada-triangular, levemente falcada; pétalas 3-5 × 1-2 mm, ereto-patentes, lanceoladotriangulares, ápice agudo, base levemente arredondada, margem curto-ciliada, brancas com manchas púrpura; labelo 5-8 × 2-3 mm, trilobado, carnoso, branco, intensamente manchado de púrpura; lobos laterais eretos, auriculares, curto-ciliados; lobo mediano carnoso, ápice arredondado, base atenuada a truncada, calo púrpura escuro, ca. $1 \mathrm{~mm}$ alt., margens freqüentemente onduladas, margem lateral levemente involuta; coluna 3-5 × 1-2 mm, branca com manchas púrpura na face ventral e nas estelídias, dois braços eretos, sinuosos e dois dentes falcados na face ventral.

Material examinado: BRASIL. BAHIA: Abaíra, Serra do Atalho, 10-VIII-1995, F. França \& E. Melo 4386 (HUEFS); Lençóis, Chapadinha, 12-XI-2001, P.L. Ribeiro et al. 87 (HUEFS); Morro do Chapéu, Morrão, 11-XI-2001, P.L. Ribeiro et al. 88 (HUEFS); 9-VIII-2003, P.L. Ribeiro et al. 26 (HUEFS); P.L. Ribeiro et al. 27 (HUEFS); 16-VII-1979, G. Hatschbach 42392 (SP); 5 km de Morro do Chapéu, estrada para Utinga, 19-IV-2001, E. Melo 3294 (SP); Palmeiras, próximo ao Morro Pai Inácio, base da Serra da Bacia, 31-I-2000, A.L.V. Toscano-de-Brito, 2228 (HUEFS); Rio de Contas, próximo ao rio Fanedo, 6-I-2000, L.P. Felix 9509 (HUEFS); Piatã, Serra do Atalho, campo rupestre, 11-VI-1992, W. Ganev 477 (HUEFS); Umburanas, Serra do Curral Feio, 9-IV-1999, L.P. Queiroz 5164 (HUEFS).

Bulbophyllum ipanemense está amplamente distribuída e é a espécie mais abundante do gênero na Chapada Diamantina. Pertence a um complexo de taxonomia bastante difícil e controversa incluído na sect. Didactyle (Pabst \& Dungs 1975). Exemplares dessa espécie foram identificados por Toscano-de-Brito (1995) como pertencentes a $B$. ipanemense, ocorrendo no Pico das Almas, em Rio de Contas, embora, o autor tenha afirmado que a espécie era intimamente relacionada com $B$. warmingianum sendo provavelmente conspecíficas. Bulbophyllum ipanemense foi descrita originariamente para o Estado de São Paulo e é uma espécie bastante freqüente nos campos rupestres de Minas Gerais. Porém, as diferenças morfológicas detectadas entre as populações da Bahia e de Minas Gerais indicam que estas possivelmente não pertençam ao mesmo táxon, podendo se tratar de uma espécie ou subespécie nova. As principais diferenças entre as populações ocorrentes na Chapada Diamantina, em relação ao material tipo da espécie e às várias populações ocorrentes no sul de Minas Gerais, são especialmente o labelo com margem ligeiramente involuta e maior dimensão das sépalas. Estudos atualmente em desenvolvimento, envolvendo não apenas morfologia, mas também genética de populações e biologia reprodutiva, poderão auxiliar na confirmação da identidade das populações encontradas na Chapada Diamantina, bem como nos demais táxons deste complexo, sendo aqui mantida a determinação utilizada por Toscano-de-Brito (1995). Floresce de novembro a agosto.

6. Bulbophyllum laciniatum (Barb. Rodr.) Cogn., Mart. Fl. bras. 3(5):609. 1902.

Figura 2 D-F.

Epífita. Rizoma 0,5-0,7 cm compr. entre pseudobulbos, 0,2-0,3 cm diâm. Pseudobulbos 1,2-1,7 cm alt., freqüentemente enrugados, agregados. Folha 3,7-6,5 × 0,8-1,0 cm, ereto-patente, cartácea, oblonga, levemente torcida, ápice acuminado. Inflorescência: escapo 7-14 cm compr., ligeiramente curvado; raque 2-3,5 cm compr., eventualmente curvado, 4-8 flores, antese simultânea. Flores pendentes; ovário (hipanto) mais pedicelo 1-3 mm compr., obcônico, sulcado; sépalas ereto-patentes, cartáceas, espessas, oblongolanceoladas, base arredondada, ápice agudo; sépala dorsal 16-37 × 2-3 mm; sépalas laterais 16-24 ×3-6 mm, fundidas em toda a extensão e formando um pequeno mento com o pé da coluna; pétalas $3-5 \times 1-5 \mathrm{~mm}$, panduriformes, ápice agudo a obtuso, base arredondada, margem longo-ciliada; labelo 13-33 × 1-2 mm, carnoso; lobos laterais eretos, membranáceos; lobo mediano carnoso, espatulado, arredondado, longo-ciliado, base atenuada, calo ca. $0,7 \mathrm{~mm}$ altura, sulcado longitudinalmente; coluna 2-2,5 × 1-1,5 mm, com dois braços eretos ou eventualmente curvados em direção ventral, e dois dentes na face ventral.

Material examinado: BRASIL. BAHIA: Rio de Contas, povoado de Mato Grosso, s.d., A.L.V. Toscanode-Brito 1905 (HUEFS); A.L.V. Toscano-de-Brito 1907 (HUEFS); Distrito de Arapiranga, 23-X-2000, A.L.V. Toscano-de-Brito 1914 (HUEFS); Fazenda Brumadinho, margens do Rio Brumadinho, 
13-VIII-1999, A.L.V. Toscano-de-Brito 2037 (HUEFS).

Bulbophyllum laciniatum é uma epífita ocorrente em matas de galeria de Minas Gerais, Rio de Janeiro e Paraná (Pabst \& Dungs 1975). Incluída na sect. Xiphizusa, é semelhante a B. chloropterum e B. plumosum, diferenciando-se destas principalmente pelas pétalas panduriformes e labelo carnoso. Floresce de agosto a outubro.

7. Bulbophyllum manarae Foldats, Acta Bot. Venez. 3:309. 1968 .

Figura 5 A-D.

Epífita. Rizoma 0,4-0,5 cm compr. entre os pseudobulbos, 0,2 cm diâm. Pseudobulbos 1,2-1,5 cm altura, esféricos, rugosos, agregados, castanhos. Folha 3,4-6 × 1,2-2,9 cm, patente, cartácea, ovada a oblonga, ápice acuminado. Inflorescência: escapo $10 \mathrm{~cm}$ compr., curvado, rígido, castanho; raque 6,5-8cm compr., 15-18 flores com disposição espiralada, 8-9 flores em antese concomitante com duração de 3-4 dias. Flores ressupinadas por curvamento da inflorescência e torção do pedicelo; ovário (hipanto) mais pedicelo 1-1,5 mm compr., obcônico, curvado, sulcado, mesclado de verde e púrpura; sépalas eretas, ligeiramente carnosas, verdes com manchas e veios púrpura, ápice acuminado; sépala dorsal 4-5 × 2-3 mm, ovada, base arredondada; sépalas laterais 5-6 × 1-2 mm, oblongo-ovadas, base oblíqua, soldadas lateralmente; pétalas $4-5 \times 1-1,5 \mathrm{~mm}$, eretas, lanceolada-triangulares, púrpura com manchas púrpura escura no ápice, ápice agudo, base assimétrica, margem curto-ciliada, cílios púrpura; labelo 3-4 × 1-1,5 mm, trilobado, falcado, paralelo à coluna, sulcado longitudinalmente, predominantemente vinoso; lobos laterais eretos, ligeiramente membranáceos, ciliados; lobo mediano carnoso, ápice arredondado a agudo, base atenuada; coluna 2-3 × 0,5-1 mm, com dois braços bifurcados, eretos, brancos com ápices púrpura, e dois dentes eretos na face ventral.

Material examinado: BRASIL. BAHIA: Morro do Chapéu, Cachoeira do Ferro Doido, 9-VIII-2003, P.L. Ribeiro et al. 45 (HUEFS); Rio de Contas, Ponte do Coronel, 18-X-1998, A.L.V. Toscano-de-Brito 1850 (HUEFS).

Bulbophyllum manarae é uma epífita ou eventualmente rupícola, rara, encontrada em matas de galeria em ambientes úmidos. Até o momento era conhecida exclusivamente para a Venezuela (Dunsterville \& Garay 1979). Esse tipo de disjunção na distribuição tem sido mencionada para outros grupos, como Eriope crassipes Benth. e Hyptis salzmannii
Benth. (Labiatae) (Harley 1988) e foi considerado por Giulietti \& Pirani (1988) como um padrão de distribuição na flora dos campos rupestres. Os espécimes de B. manarae da Venezuela, descritos por Foldats (1968), pouco diferem dos encontrados na Chapada Diamantina. Basicamente divergem pela quantidade de flores por inflorescência: as populações da Venezuela têm inflorescência geralmente com uma a cinco flores enquanto as populações da Chapada Diamantina possuem inflorescências multifloras. Apesar de aparentemente pouco relacionada, pode ser vegetativamente confundida com as espécies do grupo de B. chloropterum, B. laciniatum e B. plumosum, porém facilmente reconhecível quando em floração pelas flores pequenas, eretas, que são pendentes nas espécies daquele grupo, e pelo labelo carnoso, reduzido. Floresce de agosto a outubro.

8. Bulbophyllum mentosum Barb. Rodr., Gen. Spec. Orchid. 1:42. 1877.

Figura $5 \mathrm{E}-\mathrm{H}$.

Rupícola. Rizoma 2-2,5 cm compr. entre os pseudobulbos, 0,4-0,7 cm diâm. Pseudobulbos 2,7-4,5 cm alt., castanho-esverdeados. Folha 5,6-8 × 2-2,5 cm, ereta, carnosa, rígida, oblonga, mesclada de púrpura e verde, ápice acuminado. Inflorescência genuflexa; escapo 20-37 cm compr., ereto, rígido, comprimido lateralmente, vinho; raque $7-10 \mathrm{~cm}$ compr., pendente, vinho, 10-20 flores, 1-2 flores em antese concomitante. Flores tubulares, pendentes; ovário (hipanto) mais pedicelo 3-5 mm compr., obcônico, púrpura; sépalas eretas, carnosas, rígidas, triangular-lanceoladas, ápice acuminado, face ventral branca com manchas transversais e contorno de margem púrpura; sépala dorsal 11-13 × 3-4 mm, base truncada; sépalas laterais 10-12 × 5-6 mm, ligeiramente falcadas, base oblíqua; pétalas 8-10 × 2-3 mm, eretas, oblongo-ovadas, ápice agudo, base arredondada, margem curto-ciliada, branca com contorno roxo escuro, base lilás, veios e manchas transversais púrpura; labelo 3-4 × 3-5 mm, carnoso, revoluto, margem curto-ciliada, verde com contorno púrpura, cílios brancos e púrpura, região do calo levemente castanho; lobos laterais involutos; lobo mediano revoluto, ápice emarginado, base atenuada; coluna 4-5 × 1-2 mm, branca com manchas púrpura no pé; dois braços eretos, verde-amarelados, dois dentes patentes na face ventral; borda da cavidade estigmática alaranjada.

Material examinado: BRASIL. BAHIA: Piatã, Serra do Atalho, 22-VIII-1992, W. Ganev 939 (HUEFS); Pai 
Inácio, Três Morros, 5-XI-1996, L.P. Queiroz PCD4081 (HUEFS); 8-XI-1996, R.M. Harley 28386 (HUEFS); Seabra, cultivado em Lençóis, 22-XII-1996, A.L.V. Toscano-de-Brito 1070 (HUEFS); 22-XII-1997, A.L.V. Toscano-de-Brito 1799 (HUEFS).

Bulbophyllum mentosum é encontrado nos campos rupestres de Minas Gerais e em formações rochosas de Santa Catarina (Pabst \& Dungs 1975). Está incluída na sect. Bulbophyllaria (Pabst \& Dungs 1975), facilmente reconhecível por ser a única do gênero no Brasil a possuir o escapo comprimido lateralmente, semelhante a uma fita. Vegetativamente assemelha-se às espécies do complexo de $B$. ipanemense, mas diferencia-se pela coloração dos pseudobulbos, que são avermelhados, e pelas folhas muito carnosas. É muito semelhante a $B$. steyermarkii Foldats, espécie da Venezuela. Floresce de agosto a dezembro.

9. Bulbophyllum napellii Lindl., Ann. Mag. Nat. Hist. 10:185. 1842.

Figura 5 I-L.

Epífita. Rizoma 1,2-1,5 cm compr. entre pseudobulbos, ca. $1 \mathrm{~mm}$ diâm. Pseudobulbos 1,2-1,4 cm alt., alongados, ligeiramente piriformes, enrugados. Folha 3-4 × 0,6 cm, ereto-patente, cartácea, oblonga, ápice acuminado. Inflorescência geralmente uniflora; escapo 3-4 cm compr., ereto. Flor ressupinada por curvamento da raque; ovário (hipanto) mais pedicelo ca. $1 \mathrm{~mm}$ compr.; sépalas membranáceas, brancas com veios púrpura, trinervadas; sépala dorsal ca. $5 \times 3 \mathrm{~mm}$, ereta, subquadrada, ápice obtuso, galeada; sépalas laterais ca. $5 \times 4 \mathrm{~mm}$, ereto-patentes, triangulares, ápice reflexo, base assimétrica; pétalas ca. $3 \times 2 \mathrm{~mm}$, eretas, membranáceas, subquadradas, ápice truncadoarredondado, base truncada, margem inteira, branco com veios púrpura; labelo ca. $6 \times 2 \mathrm{~mm}$, indistintamente trilobado, membranáceo a levemente carnoso, ligeiramente móvel, pouco articulado com o pé da coluna, trinervado, oblongo, ligeiramente panduriforme, curvado em ca. $90^{\circ}$, ápice retuso, base atenuada, margem proximal ereta; coluna ca. $3 \times 1 \mathrm{~mm}$, ereta, sem estelídias, dois dentes patentes, pé da coluna longo, ca. $5 \mathrm{~mm}$ compr.

Material examinado: BRASIL. BAHIA: Mucugê, Guiné, 11-XI-2001, A.L.V. Toscano-de-Brito 2377 (HUEFS).

Bulbophyllum napellii é epífita em mata de galeria, nos grotões, encontrada nos Estados de São Paulo, Paraná, Santa Catarina e Rio Grande do Sul (Pabst \& Dungs 1975). Assemelha-se a B. regnellii Rchb. f., diferenciando-se principalmente pelo longo pé da coluna e labelo longamente unguiculado. Eventualmente ocorrem inflorescências bifloras (exemplares coletados no Estado de São Paulo), apesar de alguns autores afirmarem que sempre possuem flores solitárias (Pabst \& Dungs 1975), utilizando essa característica para incluí-la na sect. Napellii. Floresce em novembro.

\section{Bulbophyllum plumosum (Barb. Rodr.) Cogn.,} Mart. Fl. bras. 3(5):614. 1902.

Figura 2 G-J.

Rupícola ou eventualmente epífita. Rizoma 0,4-0,6 cm compr. entre os pseudobulbos, $0,2 \mathrm{~cm}$ diam. Pseudobulbos 0,6-1,2 cm alt., fracamente tetrágonos, rugosos, agregados, castanho-esverdeados. Folha 3-6 $\times$ 0,6-1,1 cm, ereto-patente, coriácea, oblonga, ápice acuminado. Inflorescência: escapo 6-9 cm compr., curvado ou eventualmente ereto; raque 4,5-7 cm compr., ligeiramente curvada; 6-10 flores, 1-5 flores em antese concomitante. Flores pendentes; ovário (hipanto) mais pedicelo 2-3 mm compr., obcônico, sulcado; sépalas ereto-patentes, cartáceas, espessas, oblongolanceoladas, verdes com face dorsal mesclada de púrpura, ápice agudo, base cordada, margem com cílios púrpura esparsos; sépala dorsal 17-21 × 2-3 mm; sépalas laterais $18-21 \times 2 \mathrm{~mm}$, oblíquas, fundidas em toda extensão; pétalas 4-5 × 1-1,5 mm, oval-lanceoladas, densamente longo-ciliadas, base assimétrica, arredondada, ápice agudo, vinho, cílios vinho; labelo $16-19 \times 4 \mathrm{~mm}$, trilobado; lobos laterais eretos, auriculares, densamente longo-ciliados, púrpura; calo carnoso com extensão de até $1 / 4$ do labelo, ca. $5 \mathrm{~mm}$ compr., esbranquiçado; lobo mediano membranáceo, espatulado, ápice arredondado, base atenuada e longociliada, branco e vinho com veios púrpura; coluna 2-3 $\times$ 1-1,5 mm, branca com manchas vinho abaixo da antera, dois braços eretos, ligeiramente falcados, dois dentes falcados na face ventral.

Material examinado: BRASIL. BAHIA: Abaíra, Jambeiro, 31-III-1994, W. Ganev 3003 (HUEFS); Morro do Chapéu, Cachoeira do Ferro Doido, mata da base do paredão, 9-VIII-2003, P.L. Ribeiro et al. 48 (HUEFS); 9-III-2003, L.P. Queiroz 7688 (HUEFS).

Bulbophyllum plumosum é rupícola dos campos rupestres de Minas Gerais e Goiás (Pabst \& Dungs 1975). Incluída na sect. Xiphizusa, é muito confundida com B. laciniatum e B. chloropterum, diferenciandose pelas pétalas lanceoladas e labelo com região calosa medindo até $1 / 4$ de sua extensão. Floresce de março a agosto. 

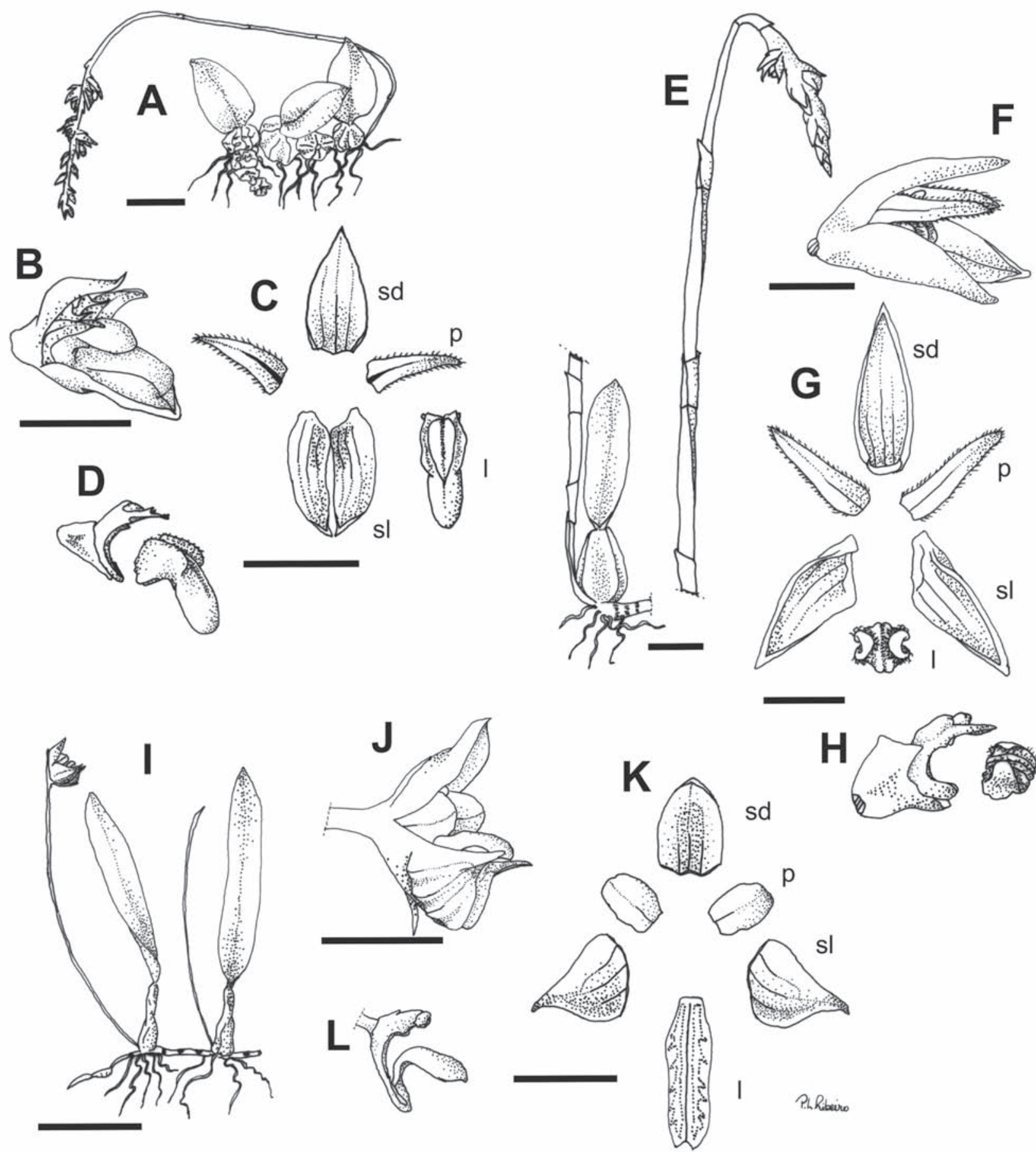

Figura 5. A-D. Bulbophyllum manarae. A. Hábito. B. Flor. C. Peças do perianto. D. Coluna e labelo, vista lateral. E-H. B. mentosum. E. Hábito. F. Flor. G. Peças do perianto. H. Coluna e labelo, vista lateral. I-L. B. napellii. I. Hábito. J. Flor. K. Peças do perianto. L. Coluna e labelo, vista lateral. 1 = labelo, $\mathrm{p}=$ pétala, $\mathrm{sd}=$ sépala dorsal, $\mathrm{sl}$ = sépala lateral. $\mathrm{O}$ labelo é apresentado em ângulo com a coluna de acordo com sua posição original, tendo sido destacado para facilitar a visualização de detalhes. Barras = 5 mm (B-D, F-H, J-L), 20 mm (A, E, I). (A-D: Ribeiro et al. 45; E-H: Toscano-de-Brito 1799; I-L: Toscano-de-Brito 2377).

Figure 5. A-D. Bulbophyllum manarae. A. Habit. B. Flower. C. Perianth parts. D. Column and lip, side view. E-H. B. mentosum. E. Habit. F. Flower. G. Perianth parts. H. Column and lip, side view. I-L. B. napellii. I. Habit. J. Flower. K. Perianth parts. L. Column and lip, side view. 1 = lip, $\mathrm{p}=$ petal, $\mathrm{sd}=$ dorsal sepal, $\mathrm{sl}=$ lateral sepal. The lip is presented in angle with the column in accordance to its original position, and it was detached to show morphological details. Bars $=5 \mathrm{~mm}(\mathrm{~B}-\mathrm{D}, \mathrm{F}-\mathrm{H}, \mathrm{J}-\mathrm{L}), 20 \mathrm{~mm}(\mathrm{~A}$, E, I). (A-D: Ribeiro et al. 45; E-H: Toscano-de-Brito 1799; I-L: Toscano-de-Brito 2377). 
11. Bulbophyllum roraimense Rolfe, Trans. Linn. Soc. London, Bot. ser. 2, 6:61. 1901.

Figura 4 H-J.

Rupícola. Rizoma ca. $2,5 \mathrm{~cm}$ compr. entre pseudobulbos, 0,5 cm diâm. Pseudobulbos 3,3-4 cm alt., verde-amarelados. Folha 6-6,6 × 2,2-2,4 cm, ereta, oblonga, ápice acuminado. Inflorescência: escapo $38-50 \mathrm{~cm}$ compr., ereto, rígido; raque $7-13 \mathrm{~cm}$ compr., levemente encurvada, 9-15 flores, 3-4 flores em antese concomitante. Flores ressupinadas pelo curvamento da raque; ovário (hipanto) mais pedicelo 3-4 mm compr., obcônico, sulcado; sépalas carnosas, levemente coriáceas, naviculadas, ápice acuminado; sépala dorsal 11-12 × 3-4 mm, ereta, oval-lanceolada, base arredondada; sépalas laterais $11-13 \times 4-5 \mathrm{~mm}$, eretopatentes, lanceolado-triangulares, levemente falcada, base assimétrica; pétalas 6-7 × $2 \mathrm{~mm}$, eretas, oblongoovadas, ápice acuminado, base arredondada e assimétrica, margem curto-ciliada; labelo 4-5 ×2-3 mm, trilobado, carnoso, móvel, articulado com o pé da coluna, paralelo a ela; lobos laterais eretos, membranáceos, auriculares, ciliados; lobo mediano carnoso, calo tomando $2 / 3$ da extensão do labelo, sulcado longitudinalmente, margem lateral revoluta, ápice agudo, base atenuada e contínua com os lobos laterais, calo ca. 1,5 $\mathrm{mm}$ alt.; coluna 4-5 $\times 1-2 \mathrm{~mm}$, dois braços eretos, sinuosos e dois dentes curtos e levemente falcados sob os braços na face ventral.

Material examinado: BRASIL. BAHIA: Palmeiras, I-1997, A.L.V. Toscano-de-Brito 1069 (HUEFS); s.d., A.L.V. Toscano-de-Brito 1800 (HUEFS).

Bulbophyllum roraimense é rupícola em campos rupestres, de ocorrência rara. Pertence ao complexo $B$. ipanemense, e era considerada endêmica da Venezuela, apesar de esperada a sua ocorrência na Amazônia brasileira. Sua ocorrência nos campos rupestres da Chapada Diamantina reforça a relação entre o Planalto das Guianas e a Cadeia do Espinhaço, evidenciada por outros grupos taxonômicos com este padrão disjunto (Harley 1988, Giulietti \& Pirani 1988) e pela ocorrência de espécies da Venezuela muito semelhantes às ocorrentes no Brasil, como é o caso de B. meridense Rchb.f. e $B$. roraimense, que se assemelham às espécies do complexo de B. ipanemense. Floresce em janeiro.

12. Bulbophyllum weddellii (Lindl.) Rchb.f., Walp. Ann. Bot. Syst. 6:251. 1861.

Figura 6 A-D.

Rupícola. Rizoma 1,6-2,6 cm compr. entre pseudobulbos, 0,4-0,5 cm diâm. Pseudobulbos 2-3 cm alt., verde-amarelados. Folha 4,2-6,3 × 1,4-2,4 cm, eretopatente, oblonga, ápice acuminado. Inflorescência genuflexa; escapo 20-42 cm compr., ereto, rígido, amarelado; raque 5-9 cm compr., 15-19 flores, raque amarelada, pendente, 5-14 flores em antese concomitante. Flores ressupinadas pela posição pendente da raque; ovário (hipanto) mais pedicelo 3-4 mm compr., obcônico, sulcado, amarelado; sépalas 13-15 × 3-4 mm, cartáceas a levemente carnosas, naviculadas, ápice agudo apiculado, face dorsal verde-amarelada, face ventral amarelada com manchas púrpura transversais e base branca; sépala dorsal ereta, oval-lanceolada; sépalas laterais ereto-patentes, oblongo-lanceoladas, levemente falcadas, margem fundida no ápice, base oblíqua formando um mento; pétalas 2-3 × 0,5-1 mm, eretas, triangulares, falcadas, ápice agudo, levemente curvado, base oblíqua, margem inteira; labelo 11-15 × 3-4 mm, trilobado, pendente; lobos laterais eretos, auriculares, curto-ciliados, púrpura escuro; lobo mediano membranáceo, ápice subagudo a obtuso, base atenuada, branco com manchas púrpura, calo carnoso, levemente sulcado, púrpura-escuro, 0,5-1 mm alt.; coluna $4 \times$ 1-2 mm, dois braços eretos, sinuosos e dois dentes curtos na face ventral.

Material examinado: BRASIL. BAHIA: Mucugê, Parque Municipal de Mucugê, Capão de Boiadeiro, 12-VI-2002, C. Azevedo 140 (HUEFS); rodovia para Andaraí, 16-VI-1984, G. Hatschbach 47975 (ALCB); Rio de Contas, base do Pico das Almas, caminho para o Campo do Queiroz, 10-I-2000, A.L.V. Toscano-de-Brito 2144 (HUEFS); s.d., A.L.V. Toscano-de-Brito 2290 (HUEFS).

Bulbophyllum weddellii é uma espécie exclusivamente rupícola, de ocorrência comum nos campos rupestres da Cadeia do Espinhaço de Minas Gerais e Bahia, também citada para o Rio de Janeiro (Pabst \& Dungs 1975, Toscano-de-Brito 1995). Espécie com flores entre as maiores do gênero no Brasil, e de fácil reconhecimento devido à inflorescência genuflexa, sépalas longas e labelo pendente. Eventualmente hibridiza com $B$. involutum, dando origem ao híbrido natural B. $\times$ cipoense (Borba \& Semir 1998a). Floresce de janeiro a junho.

13. Bulbophyllum $\times$ cipoense Borba \& Semir, Lindleyana 13(2): 113-120. 1998.

Figura 6 E-H.

Rupícola. Rizoma 2-2,5 cm compr. entre pseudobulbos, 0,3-0,4 cm diâm. Pseudobulbos 2-2,2 cm alt., verde-amarelados. Folha 8-10 × 1,7-2 cm, ereto- 


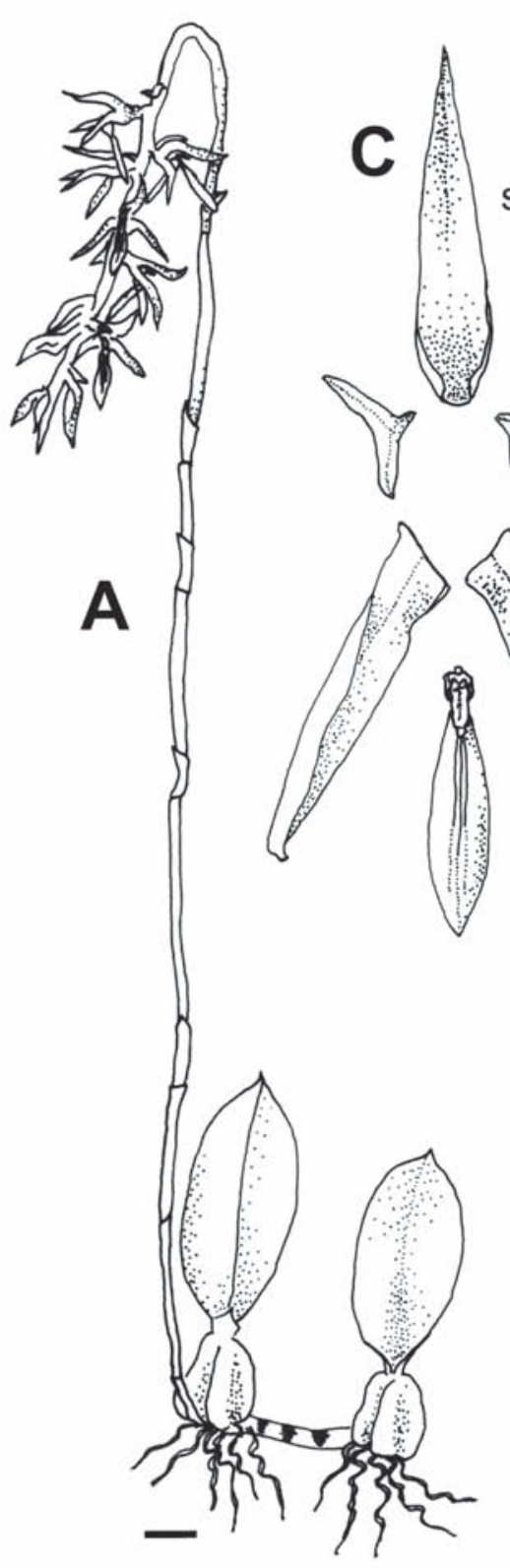

sd
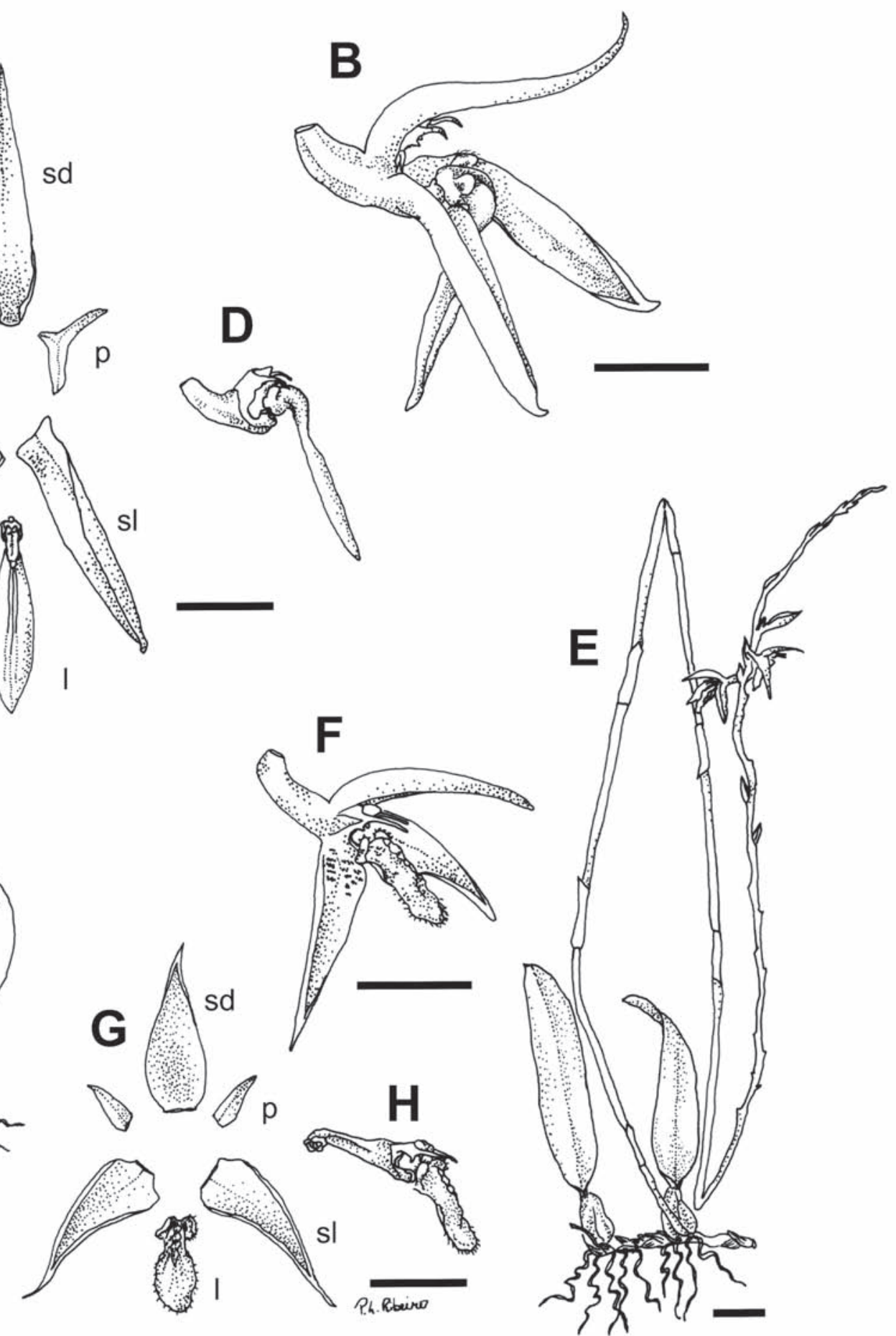

Figura 6. A-D. Bulbophyllum weddellii. A. Hábito. B. Flor. C. Peças do perianto. D. Coluna e labelo, vista lateral. E-H. B. xcipoense. E. Hábito. F. Flor. G. Peças do perianto. H. Coluna e labelo, vista lateral. 1 = labelo, $\mathrm{p}=$ pétala, $\mathrm{sd}=$ sépala dorsal, $\mathrm{sl}=$ sépala lateral. O labelo é apresentado em ângulo com a coluna de acordo com sua posição original, tendo sido destacado para facilitar a visualização de detalhes. Barras $=5 \mathrm{~mm}$ (B-D, F-H), 20 mm (A, E). (A-D: Toscano-de-Brito 2144; E-H: Azevedo 182).

Figure 6. A-D. Bulbophyllum weddellii. A. Habit. B. Flower. C. Perianth parts. D. Column and lip, side view. E-H. B. $\times$ cipoense. E. Habit. F. Flower. G. Perianth parts. H. Column and lip, side view. $1=$ lip, $p=$ petal, $s d=$ dorsal sepal, $s \mathrm{l}=$ lateral sepal. The lip is presented in angle with the column in accordance to its original position, and it was detached to show morphological details. Bars $=5 \mathrm{~mm}$ (B-D, F-H), 20 mm (A, E). (A-D: Toscano-de-Brito 2144; E-H: Azevedo 182). 
patente, espessa, oblonga, ápice acuminado. Inflorescência: escapo ca. $55 \mathrm{~cm}$ compr., ereto, rígido, amarelado; raque ca. $32 \mathrm{~cm}$ compr., ca. 17 flores, raque púrpura. Flores ressupinadas por torção do pedicelo, 3-4 flores em antese concomitante; ovário (hipanto) mais pedicelo ca. $6 \mathrm{~mm}$ compr., obcônico, torcido, púrpura; sépalas cartáceas, espessas, naviculadas, ovallanceoladas, creme com máculas vinho, manchas e pontuações púrpura na base, ápice acuminado, base arredondada; sépala dorsal ca. 9-10 × 3-4 mm, ereta; sépalas laterais $11 \times 3-4 \mathrm{~mm}$, patente, levemente falcada, oblíqua; pétalas ca. 3-4 × $1 \mathrm{~mm}$, ereto-patentes, membranáceas, lanceolado-triangulares, ápice agudo, margem inteira, creme com manchas púrpura; labelo ca. 5-6 $\times$ 2-3 mm, trilobado, carnoso, creme e intensamente manchado e pontuado de púrpura; lobos laterais eretos, auriculares, ciliados, base com pequeno calo transversal; lobo mediano carnoso, ápice arredondado, base atenuada, calo púrpuro escuro, ca. 1 $\mathrm{mm}$ alt., margens freqüentemente onduladas e ciliadas, margem lateral involuta; coluna ca. $5 \times 1-2 \mathrm{~mm}$, ereta, dois braços eretos ligeiramente curvados para o ventre e dois dentes falcados sob os braços na face ventral.

Material examinado: BRASIL. BAHIA: Mucugê, Parque Municipal de Mucugê, Córrego do Morro Fervido, 18-III-2003, C. Azevedo 182 (HUEFS).

Bulbophyllum xcipoense Borba \& Semir é um híbrido natural resultante do cruzamento entre $B$. involutum e $B$. weddellii, recentemente descrito para a Serra do Cipó, na Cadeia do Espinhaço em Minas Gerais, com base em estudos de morfologia e biologia reprodutiva (Borba \& Semir 1998a). Segundo os autores, os parentais, B. involutum e $B$. weddellii, ocorrem simpatricamente ao longo da Cadeia do Espinhaço, são intercompatíveis, possuem eventos fenológicos sincronizados e apresentam os mesmos polinizadores (Borba \& Semir, 1998b; Borba et al. 1999). Os indivíduos encontrados na Chapada Diamantina e na Serra do Cipó são morfologicamente muito similares, embora os indivíduos da Chapada Diamantina não apresentem pétalas falcadas com margem ciliada e o tamanho do labelo seja menor (8,9-9 mm compr. na Serra do Cipó). Apesar da presença de características semelhantes aos parentais, Borba \& Semir (1998a) destacam que o híbrido possui um alto grau de esterilidade ou autoincompatibilidade, sendo as diferenças em características como ângulo formado pelo labelo e coluna sejam definitivas para ineficiência da polinização. C.O. Azevedo, E.L. Borba \& C. van den Berg (submetido) testaram a hipótese de origem por hibridação deste táxon através da eletroforese de isoenzimas, utilizando 14 indivíduos de possíveis híbridos. A variabilidade genética encontrada em $B$. $\times$ cipoense indica que os indivíduos foram originados por múltiplos eventos de hibridação ou que os híbridos estão se reproduzindo na natureza, ocorrendo retrocruzamento com B. involutum, o que causa introgressão, diferentemente do observado na Serra do Cipó (Borba \& Semir 1998a).

Agradecimentos - Aos Drs. Cássio van den Berg e Nádia Roque e aos dois assessores anônimos pelos comentários e sugestões, e ao CNPq pela concessão de bolsa de Iniciação Científica a P.L. Ribeiro (IMSEAR) e de Produtividade em Pesquisa a E.L. Borba (PQ2).

\section{Referências bibliográficas}

AZEVEDO, C.O. 2004. A família Orchidaceae no Parque Municipal de Mucugê, Bahia, Brasil. Dissertação de mestrado, Universidade Estadual de Feira de Santana, Feira de Santana.

BORBA, E.L. \& SEMIR, J. 1998a. Bulbophyllum $\times$ cipoense (Orchidaceae), a new natural hybrid from the Brazilian campos rupestres: description and biology. Lindleyana 13:113-120.

BORBA, E.L. \& SEMIR, J. 1998b. Wind-assisted fly pollination on three species of Bulbophyllum (Orchidaceae) occurring in the Brazilian campos rupestres. Lindleyana 13:201-218.

BORBA, E.L., SEMIR, J. \& BARROS, F. 1998. Bulbophyllum involutum Borba, Semir \& F. Barros (Orchidaceae), a new species from the Brazilian "campos rupestres". Novon 8:225-229.

BORBA, E.L., SHEPHERD, G.J. \& SEMIR, J. 1999. Reproductive systems and crossing potential in three species of Bulbophyllum (Orchidaceae) occurring in the Brazilian "campos rupestres" vegetation. Plant Systematics and Evolution 217:205-214.

BORBA, E.L., FELIX, J.M., SOLFERINI, V.N. \& SEMIR, J. 2001a. Fly-pollinated Pleurothallis (Orchidaceae) species have high genetic variability: evidence from isozyme markers. American Journal of Botany 88:419-428.

BORBA, E.L., TRIGO, J.R. \& SEMIR, J. 2001b. Variation of diastereoisomeric pyrrolizidine alkaloids in Pleurothallis (Orchidaceae). Biochemical Systematics and Ecology 29:45-52.

BORBA, E.L., SHEPHERD, GJ., VANDENBERG, C. \& SEMIR, J. 2002. Floral and vegetative morphometrics of five Pleurothallis (Orchidaceae) species: correlation with taxonomy, phylogeny, genetic variability and pollination systems. Annals of Botany 90:219-230. 
CONCEIÇÃO, A.A. \& GIULIETTI, A.M. 2002. Composição florística e aspectos estruturais de campo rupestre em dois platôs do Morro do Pai Inácio, Chapada Diamantina, Bahia, Brasil. Hoehnea 29:37-48.

COGNIAUX, A. 1898-1902. Orchidaceae. In Flora Brasiliensis (C.F.P. Martius \& A.G. Eichler, eds.). F. Fleischer, Lipsiae, v.3, pars 5, p.1-664.

DRESSLER, R.L. 1981. The orchids: natural history and classification. Harvard University Press, Cambridge.

DRESSLER, R.L. 1993. Phylogeny and classification of the orchid family. Dioscorides Press, Cambridge.

DUNSTERVILLE, G.C.K. \& GARAY, L.A. 1979. Orchids of Venezuela - An illustrated field guide, v. 1. Botanical Museum of Harvard University, Cambridge.

FOLDATS, E. 1968. Contribuicion a la orquidiflora de Venezuela. Acta Botanica Venezuelica 3:309-311.

GIULIETTI, A.M. \& PIRANI, J.R. 1988. Patterns of geographic distribution of some plant species from the Espinhaço range, Minas Gerais and Bahia, Brazil. In Proceedings of a Workshop on neotropical distribution patterns (P.E. Vanzolini \& W.R. Heyer, eds.). Academia Brasileira de Ciências, Rio de Janeiro, p.39-69.

GRILLO, A.A.S. 2000. Aspectos pedológicos, ecológicos e florísticos de uma área de cerrado no município de Palmeiras, Chapada Diamantina, Bahia. Dissertação de mestrado, Universidade de São Paulo, São Paulo.

HARLEY, R.M. 1988. Evolution and distribution of Eriope (Labiatae), and its relatives, in Brazil. In Proceedings of a Workshop on neotropical distribution patterns (P.E. Vanzolini \& W.R. Heyer, eds.). Academia Brasileira de Ciências, Rio de Janeiro, p.71-120.
HARLEY, R.M. 1995. Introduction. In Flora of the Pico das Almas (B.L. Stannard, ed.). Royal Botanic Gardens, Kew, p.1-40.

HOLMGREN, P.K., HOLMGREN, N.H. \& BARNET, L.C. 1990. Index Herbariorum: Part I: The Herbaria of the World. New York Botanical Garden, New York.

JOLY, A.B. 1970. Conheça a vegetação brasileira. EDUSP, São Paulo.

MORI, S.A., SILVA, L.A.M., LISBOA, G. \& CORADIN, L. 1985. Manual de manejo do herbário fanerogâmico. Centro de Pesquisas do Cacau, Itabuna.

PABST, G.F.J. \& DUNGS, F. 1975. Orchidaceae Brasiliensis, v. 1. Kurt Schmersow, Hildeshein.

PABST, G.F.J. \& DUNGS, F. 1977. Orchidaceae Brasiliensis, v. 2. Kurt Schmersow, Hildeshein.

PRIDGEON, A.M. \& CHASE, M.W. 2001. A phylogenetic reclassification of the Pleurothallidinae (Orchidaceae). Lindleyana 16:235-271.

SILVA, U.F., BORBA, E.L., SEMIR, J. \& MARSAIOLI, A.J. 1999. A simple solid injection device for the analyses of Bulbophyllum (Orchidaceae) volatiles. Phytochemistry 50:31-34.

TOSCANO-DE-BRITO, A.L.V. 1995. Orchidaceae. In Flora of the Pico das Almas (B.L. Stannard, ed.). Royal Botanic Gardens, Kew, p.725-767.

TOSCANO-DE-BRITO, A.L.V. 2000. Two new species of Orchidaceae from Brazil. Lindleyana 15:184-188.

VERMEULEN, J.J. 1991. Orchids of Borneo, v. 2. Bulbophyllum. Royal Botanic Gardens, Kew.

VAN DEN BERG, C. \& CHASE, M.W. 2000. Nomenclatural notes on Laeliinae - I. Lindleyana 15:115-119. 